\title{
Risk factors for tuberculosis among HIV-infected patients in Switzerland
}

\author{
P. Sudre*, B. Hirschel*, L. Toscani**, B. Ledergerber ${ }^{+}$, H.L. Rieder ${ }^{++}$, \\ and the Swiss HIV Cohort Study
}

Risk factors for tuberculosis among HIV-infected patients in Switzerland. P. Sudre, B. Hirschel, L. Toscani, B. Ledergerber, H.L. Rieder, and the Swiss HIV Cohort Study. (C)ERS Journals Ltd 1996.

ABSTRACT: The aim of this study was to determine the risk factors associated with tuberculosis among human immunodeficiency virus (HIV)-infected persons living in Switzerland, a country with low prevalence of tuberculous infection.

We performed a nested case-control study and logistic regression. Cases $(\mathbf{n}=239)$ were patients participating in the Swiss-HIV Cohort study $(n=7,103)$, diagnosed with bacteriologically confirmed tuberculosis. The rest of the cohort population was used as control.

Patients from industrialized countries had a risk of tuberculosis similar to those from Switzerland (adjusted odds ratio (OR) 1.1; 95\% confidence interval $(95 \%$ CI) 0.7-1.5); whereas the risk among patients from Eastern Europe (OR 2.8, 95\% CI 1.9-3.7), Brazil (OR 10.6; 95\% CI 9.6-11.5), and Africa (OR 3.0; 95\% CI 2.4-3.6) was markedly higher. Immune suppression, as indicated by low CD4+ cell count, was an independent risk factor for tuberculosis (OR 7.8; 95\% CI 7.3-8.3 for patients with $\mathrm{CD} 4+<50$ cells $\cdot \mathrm{mm}^{-3}$ compared to those with $\mathrm{CD} 4+>500$ cells $^{-} \mathrm{mm}^{-3}$ ). Age, sex and HIV-transmission category did not appear to increase the risk of tuberculosis after adjustment for other patient characteristics.

In conclusion, in countries of low prevalence of Mycobacterium tuberculosis infection, to originate from a country with high prevalence of tuberculosis infection and to have advanced immunodeficiency are significant risk factors for tuberculosis. They may be used to complement the tuberculin skin test in targeting patients for preventive chemotherapy.

Eur Respir J., 1996, 9, 279-283.

Triggered by the pandemic of human immunodeficiency virus (HIV) infection, tuberculosis has emerged as a major public health threat in sub-Saharan Africa and numerous other resource-poor countries over the past decade [1]. Industrialized countries have not been spared [2], particularly minorities and deprived inner-city residents of metropolitan areas in the United States [3]. In Western Europe, the decline of tuberculosis came to a halt in the late 1980s [4], but the role of HIV appears to be minor and is conspicuous in only a few countries [5], and in some large metropolitan areas [6]. Tuberculosis poses a major challenge, however, because in HIVinfected population segments it may spread rapidly [7-9], it is frequently due to drug-resistant strains [10], and it is often fatal [11-13]. Tuberculin skin tests are used to detect infection with Mycobacterium tuberculosis [14]. A positive tuberculin skin test in an HIV-infected individual is invariably associated with an increased risk of tuberculosis $[15,16]$ and, thus, requires preventive chemotherapy [5]. In most European countries, however, only a small proportion of the population is infected with $M$. tuberculosis [17], and the interpretation of test results is complicated by the use of bacille Calmette-Guérin (BCG) vaccination.
*Division of Infectious Diseases, University Hospital, Geneva, Switzerland. **Médecin Cantonal Adjointe, Geneva, Switzerland. +Division of Infectious Diseases, University Hospital, Zurich, Switzerland. ++International Union Against Tuberculosis and Lung Disease, Bern, Switzerland.

Correspondence: P. Sudre

Division des maladies infectieuses

Hôpital Cantonal Universitaire de Genève rue Micheli-du-Crest 24

$\mathrm{CH}-1211$ Genève 4

Switzerland

\section{Keywords: Case-control study}

epidemiology

human immunodeficiency virus infection risk factors

Switzerland

tuberculosis

Received: May 151995

Accepted after revision November 31995
For these reasons, and because false negative tuberculin skin test results are increasingly common with progressive immunodeficiency [18], the identification of other factors which may predict the occurrence of tuberculosis constitute a research priority. This case-control study was, thus, designed to identify such factors potentially associated with an increased risk of tuberculosis.

\section{Methods}

The Swiss HIV Cohort Study was initiated in 1988 to serve as a basis for research projects on preventive, epidemiological, clinical and laboratory aspects of HIV infection. Study design, organization, recruitment, and procedures of data collection have been described previously $[19,20]$. In brief, HIV-infected adults (aged 16 yrs and older) have been recruited in six centres in Switzerland. Information on HIV-associated diseases, medications and laboratory tests is collected at 6 month intervals according to a standard protocol. Comparability of test results is ensured with regular and standardized quality control procedures [19].

As of 30th September 1994, 7,103 HIV-infected patients have been enrolled in the study, of whom $74 \%$ were 
male $(5,221)$ and $26 \%$ female $(1,882)$. Categories of presumed transmission included: homosexuals $32 \%(2,303)$; injecting drug users (IDU) $41 \%(2,923)$; infection by heterosexual contact, $23 \%(1,651)$; and other transmission modes, $3 \%$ (226). The majority of patients $(54 \%, 3,821)$ were 26-35 yrs of age at the time of registration. Seventy nine percent $(5,591)$ were Swiss citizens, $14 \%(1,020)$ were from other countries of Western Europe, and 480 (7\%) from other parts of the world (12 patients of unknown country of origin). Patient registration started as early as 1981 but the vast majority (70\%) of patients were registered between 1988 and 1992.

In this nested case-control study, cases were HIVinfected cohort patients diagnosed with bacteriologically confirmed tuberculosis. They were compared to the rest of the patients registered in the cohort (controls). Univariate and multivariate logistic regression models were used to assess the association between the occurrence of tuberculosis and risk markers, such as: demographic characteristics of patients (age and gender); transmission category; country or region of origin; year of registration; and CD4+ cell count at the time of registration. Because the cumulative risk of disease depends on the duration of follow-up, this variable was also adjusted for. In the logistic model, all variables were coded as categorical. The dependent variable was tuberculosis and the independent variables represented the risk markers. The equation co-efficient converted to an odds ratio (OR) provided for each variable subcategory an estimate of the risk of disease adjusted for the other variables included in the model [21]. Statistical analysis was conducted with Statistical Package for the Social Sciences (SPSS) for Windows® computer programme.

There were 12 countries with at least two cases or 30 cases and controls (Austria, Brazil, France, Germany, Italy, Portugal, Spain, Switzerland, Turkey, USA, former Yugoslavia, and Zaire). Patients from other countries were grouped by region (Eastern Europe, other industrialized

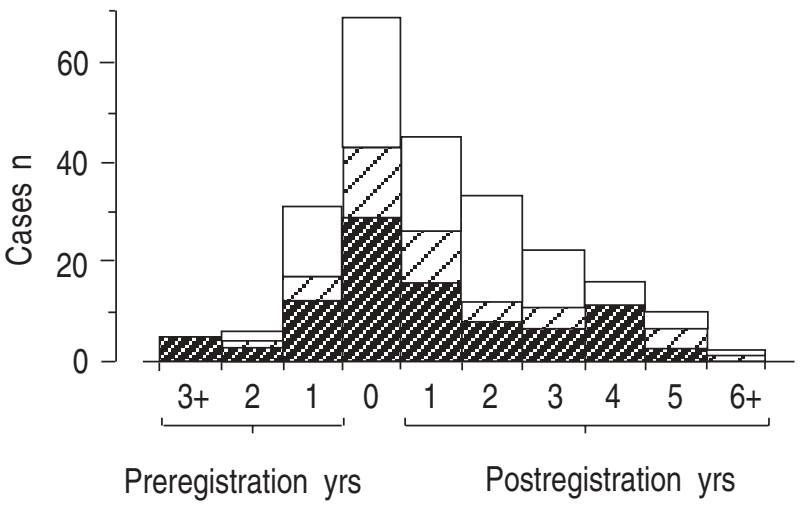

Fig. 1. - Time interval between registration in Swiss HIV Cohort Study and diagnosis of tuberculosis $(\mathrm{n}=239)$. Column " 0 " represents patients diagnosed with tuberculosis at the time of registration. HIV: human immunodeficiency virus. $\square$ : extrapulmonary TB only; $\square$ : pulmonary and extrapulmonary TB; $\square$ : pulmonary TB only.

countries, Africa, other resource-poor countries). These countries and regions were analysed separately in the univariate analysis and regrouped by geographic area in the multivariate model.

The accuracy and completeness of tuberculosis reporting was assessed in one centre (Geneva) by a comparison of the "Cantonal tuberculosis register" with the data available in the cohort. Data sources for these two reporting systems are independent and every patient from whom M. tuberculosis is isolated must be reported to the tuberculosis register. Patients with the same date of birth and sex in both registers were identified to ascertain that individuals listed in both registers were correctly reported with tuberculosis in the cohort. Out of 450 patients listed in the tuberculosis register and 1,200 HIV-infected patients from Geneva listed in the HIV cohort study, 23 had the same name, sex and date of birth. All 23 were correctly reported with the diagnosis of tuberculosis in the cohort.

Table 1. - Country* or region of origin as a risk factor for tuberculosis in the Swiss HIV Cohort Study

\begin{tabular}{|c|c|c|c|c|c|c|c|}
\hline Country/region & $\begin{array}{c}\text { Case } \\
\mathrm{n}\end{array}$ & $\begin{array}{l}\mathrm{TB} \\
\%\end{array}$ & $\begin{array}{c}\text { Controls } \\
\mathrm{n}\end{array}$ & $\begin{array}{c}\text { without TB } \\
\%\end{array}$ & $\mathrm{OR} * *$ & $(95 \% \mathrm{CI})$ & p-value \\
\hline Switzerland & 163 & 68.2 & 5428 & 79.1 & 1.0 & & \\
\hline Austria & 2 & 0.8 & 37 & 0.5 & 1.8 & $(0.4-7.5)$ & NS \\
\hline Brazil & 6 & 2.5 & 28 & 0.4 & 7.1 & $(2.9-17.5)$ & $<0.01$ \\
\hline France & 5 & 2.1 & 181 & 2.6 & 0.9 & $(0.4-2.3)$ & NS \\
\hline Germany & 4 & 1.7 & 107 & 1.6 & 1.2 & $(0.5-3.4)$ & NS \\
\hline Italy & 10 & 4.2 & 335 & 4.9 & 1.0 & $(0.5-1.9)$ & NS \\
\hline Portugal & 6 & 2.5 & 73 & 1.1 & 2.7 & $(1.2-6.4)$ & $<0.05$ \\
\hline Spain & 6 & 2.5 & 183 & 2.7 & 1.1 & $(0.5-2.5)$ & NS \\
\hline Turkey & 2 & 0.8 & 22 & 0.3 & 3.0 & $(0.7-13.0)$ & NS \\
\hline USA & 0 & 0.0 & 32 & 0.5 & $0.0 \mathrm{Un}$ & hed & \\
\hline Yugoslavia & 2 & 0.8 & 33 & 0.5 & 2.0 & $(0.5-8.5)$ & NS \\
\hline Zaire & 4 & 1.7 & 57 & 0.8 & 2.3 & $(0.8-6.5)$ & NS \\
\hline Other Eastern European & 2 & 0.8 & 27 & 0.4 & 2.5 & $(0.6-10.5)$ & NS \\
\hline Other industrialized & 2 & 0.8 & 82 & 1.2 & 0.8 & $(0.2-3.3)$ & NS \\
\hline Other African & 14 & 5.9 & 124 & 1.8 & 3.8 & $(2.1-6.7)$ & $<0.01$ \\
\hline Other Latin American & 7 & 2.9 & 56 & 0.8 & 4.2 & $(1.9-9.3)$ & $<0.01$ \\
\hline Asia & 3 & 1.3 & 48 & 0.7 & 2.1 & $(0.6-6.8)$ & NS \\
\hline Uknown & 1 & 0.4 & 11 & 0.2 & 3.0 & $(0.4-23.6)$ & NS \\
\hline
\end{tabular}

*: countries with at least 2 cases or a total of 30 cases and controls; **: univariate logistic regression model. Uknown: unknown country of origin; TB: tuberculosis; HIV: human immunodeficiency virus; OR: odds ratio; $95 \%$ CI: $95 \%$ confidence interval; NS: nonsignificant at the 0.05 level. 


\section{Results}

There were 239 patients $(3.4 \%$ ) diagnosed with tuberculosis among the 7,103 patients in the entire cohort, of whom $94(39 \%)$ had pulmonary tuberculosis, $102(43 \%)$ had extrapulmonary tuberculosis and $43(18 \%)$ had both. Extrapulmonary tuberculosis was the first acquired immune deficiency syndrome (AIDS)-defining diagnosis for $95(66 \%)$ patients reported with AIDS. The occurrence of tuberculosis relative to the time of registration is presented in figure 1. Of all tuberculosis cases, 42 (18\%) occurred more than 2 months before registration and 69 $(29 \%)$ were diagnosed with tuberculosis and registered at the same time. Eighteen (8\%) patients had tuberculosis diagnosed at the time of death or postmortem. Although tuberculosis could be at least implicated as a contributing factor to death in this group, detailed information of tuberculosis-specific mortality was not available. The average CD4+ cell count for 168 patients whose CD4+ cells were measured within 3 months of tuberculosis diagnosis was
167 cells $\cdot \mathrm{mm}^{-3}$. The CD4+ cell count was 209 cells $\cdot \mathrm{mm}^{-3}$ for pulmonary tuberculosis, 133 cells $\cdot \mathrm{mm}^{-3}$ for extrapulmonary tuberculosis, and 171 cells $\cdot \mathrm{mm}^{-3}$ for patients with both. The difference in mean CD4+ cell count between pulmonary and extra-pulmonary tuberculosis was statistically significant $(\mathrm{p}<0.05)$.

About $32 \%$ of tuberculosis cases (76) occurred among patients who were not Swiss nationals (table 1). The risk of tuberculosis was similar for Swiss, patients from most Western European countries (Austria, France, Germany, Italy and Spain) and other industrialized countries with the exception of Portugal (OR 2.7; 95\% confidence interval (95\% CI) 1.2-6.4). The risk of disease was also significantly increased among patients from Brazil (OR 7.1; 95\% CI 6.2-8.0), Africa (OR 3.8; 95\% CI 2.1-6.7) and Latin America (OR 4.2; 95\% CI 1.9-9.3) compared to Swiss nationals. Patients from countries of Eastern Europe, Turkey, Zaire, Yugoslavia and Asia also had an increased risk of disease, which was not statistically significant.

Table 2. - Risk factors for tuberculosis in the Swiss HIV Cohort Study

\begin{tabular}{|c|c|c|c|c|c|c|c|c|c|c|}
\hline & Cases w & h TB & Controls & hout TB & OR & $(95 \% \mathrm{CI})$ & $\mathrm{p}$-value & $\mathrm{OR}^{* *}$ & $(95 \% \mathrm{CI})$ & $\mathrm{p}$-value \\
\hline & $\mathrm{n}$ & $\%$ & & & & & & & & \\
\hline Sex & & & & & & & & & & \\
\hline Male & 191 & 80 & 5030 & 73 & 1 & & & 1 & & \\
\hline Female & 48 & 20 & 1834 & 27 & 0.7 & $(0.4-1.0)$ & NS & 0.8 & $(0.4-1.2)$ & NS \\
\hline Age yrs & & & & & & & & & & \\
\hline$<25$ & 31 & 13 & 1251 & 18 & 1 & & & 1 & & \\
\hline $26-35$ & 134 & 56 & 3687 & 54 & 1.5 & $(1.1-1.9)$ & $<0.05$ & 1.1 & $(0.7-1.6)$ & NS \\
\hline $36-45$ & 54 & 23 & 1262 & 18 & 1.7 & $(1.3-2.2)$ & $<0.05$ & 1.3 & $(0.8-1.8)$ & NS \\
\hline$>45$ & 20 & 8 & 664 & 10 & 1.2 & $(0.6-1.8)$ & NS & 0.9 & $(0.3-1.6)$ & NS \\
\hline Transmission & & & & & & & & & & \\
\hline Homosexual & 82 & 34 & 2221 & 32 & 1 & & & 1 & & \\
\hline Heterosexual & 62 & 26 & 1589 & 23 & 1.1 & $(0.7-1.4)$ & NS & 1.2 & $(0.8-1.6)$ & NS \\
\hline IVDU & 92 & 39 & 2831 & 41 & 0.9 & $(0.6-1.2)$ & NS & 1.2 & $(0.9-1.6)$ & NS \\
\hline Others & 3 & 1 & 223 & 3 & 0.4 & $(0.0-1.5)$ & NS & 0.3 & $(0.0-1.7)$ & NS \\
\hline Country or region & n of or & & & & & & & & & \\
\hline Switzerland & 163 & 68.2 & 5428 & 79.1 & 1 & & & 1 & & \\
\hline $\begin{array}{l}\text { Industrialized } \\
\text { countries }\end{array}$ & 29 & 12.1 & 953 & 13.9 & 1.0 & $(0.6-1.4)$ & NS & 1.1 & $(0.7-1.5)$ & NS \\
\hline Portugal & 6 & 2.5 & 73 & 1.1 & 2.7 & $(1.9-3.6)$ & $<0.05$ & 3.0 & $(2.1-3.9)$ & $<0.05$ \\
\hline Eastern Europe & 6 & 2.5 & 82 & 1.2 & 2.4 & $(1.6-3.3)$ & $<0.05$ & 2.8 & $(1.9-3.7)$ & $<0.05$ \\
\hline Brazil & 6 & 2.5 & 28 & 0.4 & 7.1 & $(6.2-8.0)$ & $<0.01$ & 10.6 & $(9.6-11.5)$ & $<0.01$ \\
\hline Africa & 18 & 7.5 & 181 & 2.6 & 3.3 & $(2.8-3.8)$ & $<0.01$ & 3.0 & $(2.4-3.6)$ & $<0.01$ \\
\hline Other resource-poor & or 10 & 4.2 & 108 & 1.6 & 3.1 & $(2.4-3.7)$ & $<0.05$ & 2.7 & $(2.0-3.5)$ & $<0.05$ \\
\hline Unknown & 1 & 0.4 & 11 & 0.2 & 3.0 & $(1.0-5.1)$ & NS & 2.1 & $(0.0-4.3)$ & NS \\
\hline Duration of follow- & w-up I & onths & & & & & & & & \\
\hline$<6$ & 51 & 21 & 1782 & 26 & 1 & & & 1 & & \\
\hline $6-12$ & 21 & 9 & 725 & 11 & 1.0 & $(0.5-1.5)$ & NS & 0.9 & $(0.3-1.5)$ & NS \\
\hline $13-24$ & 55 & 23 & 1347 & 20 & 1.4 & $(1.0-1.8)$ & $<0.05$ & 1.2 & $(0.8-1.7)$ & NS \\
\hline $25-36$ & 45 & 19 & 1055 & 15 & 1.5 & (1.1-1.9) & $<0.05$ & 1.7 & $(1.2-2.1)$ & $<0.05$ \\
\hline$>36$ & 67 & 28 & 1955 & 29 & 1.2 & $(0.8-1.6)$ & NS & 1.6 & $(1.1-2.0)$ & $<0.05$ \\
\hline Total & 239 & & 6864 & & & & & & & \\
\hline CD4+ at registratio & tion ce & $\mathbf{s} \cdot \mathbf{m m}$ & & & & & & & & \\
\hline$>500$ & 24 & 10 & 2147 & 31 & 1 & & & 1 & & \\
\hline $201-500$ & 77 & 32 & 2351 & 34 & 2.9 & $(2.5-3.4)$ & $<0.01$ & 3.0 & $(2.5-3.5)$ & $<0.01$ \\
\hline $51-200$ & 72 & 30 & 1397 & 20 & 4.6 & $(4.1-5.1)$ & $<0.01$ & 4.9 & $(4.4-5.4)$ & $<0.01$ \\
\hline$<50$ & 51 & 21 & 703 & 10 & 6.5 & $(6.0-7.0)$ & $<0.01$ & 7.8 & $(7.3-8.3)$ & $<0.01$ \\
\hline Total & 224 & & 6898 & & & & & & & \\
\hline
\end{tabular}

*: univariate logistic regression; **: multiple logistic regression model adjusted for sex, age, transmission category, country of origin, duration of follow-up and CD+ cell count at registration $(n=6,822)$. IVDU: intravenous drug user; AOR: adjusted odds ratio. For further abbreviations see legend to table 1. 
The multivariate comparison of patients with tuberculosis with those who remained free of disease is presented in table 2. The risk of disease was similar in all the presumed HIV-transmission groups. The apparent increased risk of tuberculosis for males and patients aged 26-45 yrs was moderate and no longer statistically significant after adjustment. Similarly, the risk of tuberculosis was not associated with the year of registration after adjustment. As expected, duration of follow-up was an important confounding variable associated with an increased risk of disease occurrence as well as several risk factors investigated.

The country or the region of origin remained the strongest risk factor when other variables were adjusted for. With the exception of patients from Portugal (adjusted OR (AOR) 3.0; 95\% CI 2.1-3.9) patients from industrialized countries and Swiss natives had a similar risk of disease. Patients from Brazil had more than 10 times (AOR 10.6; 95\% CI 9.6-11.5), and African-born patients more than three times (AOR 3.0; 95\% CI 2.4-3.6) the risk of tuberculosis compared to patients from Switzerland. Patients from Eastern Europe as well as those from resource-poor countries also had an increased risk of tuberculosis.

Low CD4+ cell count at the time of registration was strongly associated with increased risk of tuberculosis. Patients with less than $50 \mathrm{CD} 4+$ cells $\cdot \mathrm{mm}^{-3}$ were almost eight times more likely (AOR 7.8; 95\% CI 7.3-8.3) and those with 50-200 CD4+ cells $\mathrm{mm}^{-3}$ more than four times more likely (AOR 4.9; 95\% CI 4.4-5.4) to have tuberculosis than those with more than $500 \mathrm{CD} 4+$ cells $\cdot \mathrm{mm}^{-3}$.

\section{Discussion}

In this study, a nested case-control method was used to identify risk factors for tuberculosis among HIV-infected patients in Switzerland. Cases included all patients who developed bacteriologically confirmed tuberculosis prior to and after registration in the Swiss HIV Cohort Study, and all patients who did not have tuberculosis were included in the control group. Retrospective and followup information available in the cohort was used to compare two large groups of patients and assess risk factors for a relatively rare disease.

Of 7,103 HIV-infected persons registered in the cohort, $3.4 \%$ were diagnosed with tuberculosis. About half had extrapulmonary tuberculosis which was, in general, the first AIDS defining event. The average CD4+ cell count was significantly lower at the time of diagnosis in patients with extrapulmonary than in patients with pulmonary tuberculosis. With the exception of patients from Portugal, patients from countries of the European Union and industrialized countries of North America and Asia had a risk of tuberculosis similar to those from Switzerland. On the other hand, patients from countries of Eastern Europe and resource-poor countries of Africa, Asia and Latin America had a markedly higher risk of tuberculosis than those from Switzerland. Immune suppression, as indicated by low CD4+ cell count was also a significant risk factor for tuberculosis. Age, sex, transmission category and year of registration did not appear to increase the risk of tuberculosis after adjustment for other patient characteristics.

Tuberculosis was relatively rare among HIV-infected patients followed in this cohort. Underreporting seems unlikely, as register matching in one centre did not identify any patients in the cohort where the diagnosis of tuberculosis was not reported. The observed low incidence of tuberculosis may also be due to the introduction of preventive chemotherapy among patients with positive tuberculin skin test. This is unlikely, however, as only a small proportion of patients were skin tested, because the incidence of tuberculosis was low and similar regardless of skin test results [22], and because the introduction of chemotherapy was slow and progressive. In effect, there is no evidence that tuberculosis was more common in earlier periods of the study, before the introduction of preventive chemotherapy. Study patients were fairly representative of the HIV-infected population residing in Switzerland. There is no indication that study participants were somewhat less likely to be infected with $M$. tuberculosis than most HIV-infected patients who live in Switzerland. It is estimated that $32-47 \%$ of HIV-infected patients who reside in this country and $70 \%$ of AIDS cases reported to the Federal Office of Public Health [19] are enrolled in the cohort study.

Pre-existing infection with $M$. tuberculosis is strongly associated with the occurrence of active tuberculosis among HIV-infected people [15, 16], and patients from countries where a large proportion of the adult population is infected had a significantly higher risk of disease than those from countries where the prevalence of tuberculous infection is low [17]. Patients from Portugal, the country with the highest tuberculosis notification rate in Western Europe [4] (50 per 100,000), also had an increased risk. Given patterns of immigration in Switzerland, patients from other European countries with a prevalence of infection similar to Portugal, such as Spain and Italy, who participated in this study may have resided in Switzerland for a longer period of time or may even have been born there. The risk of tuberculosis among immigrants is particularly high in the first few years after arrival in their new host country and is comparable to that in their country of origin, but subsequently appears to decrease according to some [23] but not all studies [24].

Previous observations that extrapulmonary tuberculosis tends to occur later than pulmonary tuberculosis among HIV-infected patients $[25,26]$ was confirmed by lower CD4+ cell counts at the time of extrapulmonary compared to pulmonary tuberculosis. The fact that most cases of tuberculosis (75\%) occurred among patients with CD4+ cell count below 200 cells $\cdot \mathrm{mm}^{-3}$, and that low CD4+ cell counts at the time of registration was a significant risk factor for disease was somewhat unexpected. In this study, however, this may be an artefact, as some patients were registered in the cohort because they were diagnosed with tuberculosis. Without tuberculosis, these patients would have been registered later with a lower CD4+ cell count at the time of registration and they would have served as controls rather than cases in this analysis.

The value of the tuberculin skin test to identify tuberculous infection among patients with advanced HIV 
infection and low CD4+ cell count is unfortunately limited [27], because it is precisely these patients who seem to be at increased risk of tuberculosis. Tuberculin skin testing should, therefore, be performed as early as possible and those considered to be infected should be offered preventive chemotherapy. Patients who come to the attention of the physician late in the course of their HIV infection may be considered to be infected with $M$. tuberculosis with smaller tuberculin skin test reaction sizes than immunocompetent patients [18]. The gain in sensitivity with this approach must, nevertheless, be weighed against the loss in specificity. Simultaneous testing with other recall antigens may, in part, alleviate this problem [28]. The reported cumulative incidence of tuberculosis in this study exceeded $10 \%$ in patients from Africa and Latin America. Thus, one might argue that preventive therapy in HIV-infected patients from such countries should be considered irrespective of tuberculin skin test results, because such a risk is similar to that of other groups, such as infected contacts, routinely recommended for preventive therapy.

Acknowledgements: The authors wish to thank T. Perneger, Institut de Médecine Sociale et Préventive, Geneva for helpful comments and suggestions on early discussions of methodological issues.

Centres and investigators of the Swiss HIV Cohort Study: Participating Centres: Kantonsspital Basel: M. Battegay, P. Erb; Inselspital Bern: R. Malinverni, L. Matter, W.J. Pichler; Hôpital Cantonal Universitaire de Genève: B. Hirschel, L. Perrin; Centre Hospitalier Universitaire Vaudois: Ph. Frei, J. von Overbeck; Medizinische Klinik A, St. Gallen: W. Fierz, P. Vernazza; Universitätsspital Zürich: R. Lüthy, P.J. Grob. Co-ordinating and Data Centre: P. Francioli (principal investigator); D. Knöpfli, B. Ledergerber, Th. Meister.

\section{References}

1. Raviglione MC, Snider DE Jr, Kochi A. Global epidemiology of tuberculosis: morbidity and mortality of a worldwide epidemic. J Am Med Assoc 1995; 273: 220226.

2. Cantwell MF, Snider DE Jr, Cauthen GM, Onorato IM. Epidemiology of tuberculosis in the United States, 1985 through 1992. J Am Med Assoc 1994; 272: 535-539.

3. Bloom BR, Murray CJ. Tuberculosis: commentary on a re-emergent killer. Science 1992; 257: 1055-1064.

4. Raviglione MC, Sudre P, Rieder HL, Spinaci S, Kochi A. Secular trends of tuberculosis in Western Europe. Bull WHO 1993; 71: 297-306.

5. Guelar A, Gatell JM, Verdejo J, et al. A prospective study of the risk of tuberculosis among HIV-infected patients. AIDS 1993; 7: 1345-1349.

6. Haury B, Salomon J. Les cas de tuberculose déclarés en France en 1993. Bull Epidém Hebdomadaire 1994; 44: 203-205.

7. Alland D, Kalkut GE, Moss AR, et al. Transmission of tuberculosis in New York City: an analysis by DNA fingerprinting and conventional epidemiologic methods. N Engl J Med 1994; 330: 1710-1716.

8. Edlin BR, Tokars JI, Grieco MH, et al. An outbreak of multidrug-resistant tuberculosis among hospitalized patients with the acquired immunodeficiency syndrome. N Engl J Med 1992; 326: 1514-1521.
9. Small PM, Hopewell PC, Singh SP, et al. The epidemiology of tuberculosis in San Francisco; a populationbased study using conventional and molecular methods. N Engl J Med 1994; 330: 1703-1709.

10. Genewein A, Telenti A, Bernasconi C, et al. Molecular approach to identifying route of transmission of tuberculosis in the community. Lancet 1993; 342: 841-844.

11. Fischl MA, Daikos GL, Uttamchandani RB, et al. Clinical presentation and outcome of patients with HIV infection and tuberculosis caused by multiple-drug-resistant bacilli. Ann Intern Med 1992; 117: 184-190.

12. Nunn P, Brindle R, Carpenter L, et al. Cohort study of human immunodeficiency virus infection in patients with tuberculosis in Nairobi, Kenya: analysis of early (6 month) mortality. Am Rev Respir Dis 1992; 146: 849-854.

13. Dolin PJ, Raviglione MC, Kochi A. Global tuberculosis incidence and mortality during 1990-2000. Bull WHO 1994; 72: 213-220.

14. Rieder HL, Cauthen GM, Comstock GW, Snider D Jr. Epidemiology of tuberculosis in the United States. Epidemiol Rev 1989; 11: 79-98.

15. Moreno S, Baraia Etxaburu J, Bouza E, et al. Risk for developing tuberculosis among anergic patients infected with HIV. Ann Intern Med 1993; 119: 194-198.

16. Girardi E, Antonnucci G, Ippolito G, Armignacco O, GISTA. Prospective evaluation of risk of tuberculosis in HIV-infected persons by tuberculin reaction size. Tenth International Conference on AIDS, Yokohama, Japan 1994. Abstract No. 405B: 28.

17. Sudre P, ten Dam G, Kochi A. Tuberculosis: a global overview of the situation today. Bull WHO 1992; 70: 149-159.

18. Anonymous. Purified protein derivative (PPD)-tuberculin anergy and HIV infection: guidelines for anergy testing and management of anergic persons at risk of tuberculosis. Morb Mort Weekly Rep 1991; 40: 27-32.

19. Ledergerber B, von Overbeck J, Egger M, Lüthy R. The Swiss HIV cohort study: rationale, organization and selected baseline characteristics. Soz Präventivmed 1994; 39: 387-394.

20. von Overbeck J, Egger M, Davey Smith G, et al. Survival in HIV infection: do sex and category of transmission matter? AIDS 1994; 8: 1307-1313.

21. Rothman KJ. In: Modern Epidemiology. Boston, Little, Brown and Co., 1986.

22. Sudre P, Flepp M, Ledergerber B, et al. Low incidence of TB among Swiss HIV patients. International Conference on AIDS, 1994; PB0710: 174 (Abstract).

23. McCarthy OR. Asian immigrant tuberculosis: the effect of visiting Asia. Br J Dis Chest 1984; 78: 248-253.

24. Enarson DA, Sjögren I, Grzybowski S. Incidence of tuberculosis among Scandinavian immigrants in Canada. Eur J Respir Dis 1980; 61: 139-142.

25. Barnes PF, Bloch AB, Davidson PT, Snider DE. Tuberculosis in patients with human immunodeficiency virus infection. N Engl J Med 1991; 324: 1644-1650.

26. Hopewell PC. Impact of human immunodeficiency virus infection on the epidemiology, clinical features, management, and control of tuberculosis. Clin Infect Dis 1992; 15: 540-547.

27. Theuer CP, Hopewell PC, Elias D, Schecter GF, Rutherford GW, Chaisson RE. Human immunodeficiency virus infection in tuberculosis patients. J Infect Dis 1990; 162: 8-12.

28. Subcommittee of the Joint Tuberculosis Committee of the British Thoracic Society. Guidelines on the management of tuberculosis and HIV infection in the United Kingdom. Br Med J 1992; 304: 1231-1233. 